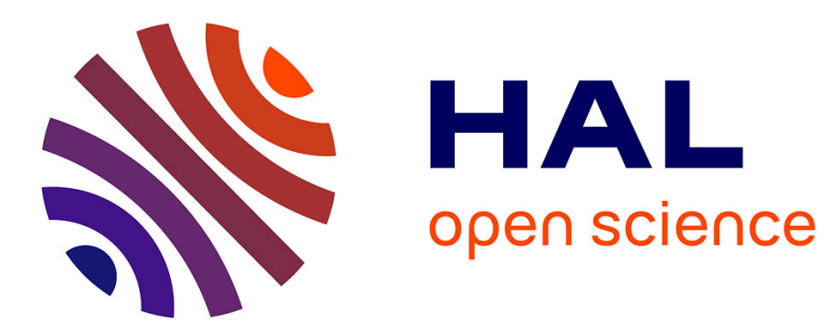

\title{
Effective Demand: Securing the Foundations
}

Olivier Allain

\section{- To cite this version:}

Olivier Allain. Effective Demand: Securing the Foundations: Olivier ALLAIN on Jochen HARTWIG (2007) and Mark HAYES (2007). 5th "Dijon" Post-Keynesian Conference, May 2011, Roskilde, Denmark. hal-00606976

\section{HAL Id: hal-00606976 https://hal.science/hal-00606976}

Submitted on 7 Jul 2011

HAL is a multi-disciplinary open access archive for the deposit and dissemination of scientific research documents, whether they are published or not. The documents may come from teaching and research institutions in France or abroad, or from public or private research centers.
L'archive ouverte pluridisciplinaire $\mathbf{H A L}$, est destinée au dépôt et à la diffusion de documents scientifiques de niveau recherche, publiés ou non, émanant des établissements d'enseignement et de recherche français ou étrangers, des laboratoires publics ou privés. 


\title{
EfFective Demand: Securing The Foundations: Olivier Allain on Jochen HARTWIG (2007) and Mark HAYES (2007)
}

\author{
Olivier ALLAIN ${ }^{1}$ \\ Université Paris Descartes \& Centre d'Economie de la Sorbonne
}

\begin{abstract}
A panel session was organised at the 5th "Dijon" Post-Keynesian Conference (Roskilde University - 13th-14th May 2011) in order to confront three recent interpretations of Keynes's principle of effective demand: that of Hartwig (2007), Hayes (2007) and Allain (2009). Allain's comments on Hartwig and Hayes articles are developed in the present contribution.
\end{abstract}

I would like to thank Mark Hayes $(\mathrm{MH})$ who had the good idea in suggesting a debate between himself, Jochen Hartwig $(\mathrm{JH})$ and me. As I did not mention their articles in mine which was however published two years later, I also would like to add that I sent my proposition to the review in 2006 and had no occasion to make any change until its publication.

Anyway, I read JH and $\mathrm{MH}$ articles with great interest. And I am glad to have the opportunity to comment them and ask questions to their authors.

JH's analysis is closed to mine on many aspects. That explains why I do not have a lot of comments/questions for him. The main divergence is about the uniqueness of the aggregate demand function (according $\mathrm{JH}$ ) and a distinction between two separate functions (according to me).

MH's analysis is much more different. I began to find it odd. But, having carefully reread some passages of the General Theory (GT) and other Keynes's writings, I finally concluded that $\mathrm{MH}$ was right on several aspects, notably on the production period issue.

\section{The production period}

It is now clear to me that Keynes's theory rests on production periods of different durations, each one comprising several days: 'on any day in any firm a number of production periods of differing lengths overlap' (Keynes, 1973, p. 180). Today employment decision then partly depends on what is expected for next days, hence the definitions of $D$ as depending on entrepreneurs' short-term expectations where short-term is not restricted to today but takes into account the future days of the production period. More precisely, $D$ depends on some receipts which spread over several days. Eventually, today effective demand is the intersection between today $Z$ and $D$ functions.

In addition, because of overlapping production periods, there is "no definite relationship between aggregate effective demand at one time and aggregate income at some other later time' (Keynes, 1973, p. 179-180) as MH shows himself concluding that ' $Y$ and $D^{*}$ are quite different' (p. 62).

\footnotetext{
${ }^{1}$ Correspondence address : Olivier Allain, Centre d'Economie de la Sorbonne, 106-112 Boulevard de l’Hôpital, 75013 Paris, France. E-mail : olivier.allain@univ-paris5.fr.
} 
In short, I must thank MH for having made it much clearer. However, let us notice that neither consumption nor investment have been mentioned here.

\section{Employers and dealers}

MH introduces further a distinction between employers and dealers which I first found odd and cumbersome before realising it makes things more comprehensible. Accordingly, $\mathrm{MH}$ claims that entrepreneurs' expectations are almost always fulfilled: 'since production is undertaken only against forward orders, the employer's expectations are fulfilled by contract, and can be disappointed only if the dealer defaults upon delivery (this would represent a windfall loss for the employer, which does not affect present or future employment decisions). Whether the dealers' expectations are fulfilled is literally a question for another day and depends on whether they have correctly judged future demand at the time of delivery in a given state of expectation...' (p. 67). As a result, if I well understood, one can say that unforeseen changes in demand are mainly bore by dealers, through windfall profits or losses. These unforeseen changes affect employers only indirectly, through the impact of market prices on forward prices. In other words, the multiplier has an effect on current market prices before it affects short-term expectations, and then tomorrow employment.

These developments are very stimulating and will fuel my further reflection. However, it seems excessive to pretend that Keynes suggests this distinction between employers and dealers while quotations in footnote no 15 do not clearly establish that point. Consequently, I think MH departs too much from Keynes's analysis. Indeed, what does remain of entrepreneurs' expectations if these 'expectations are fulfilled by contract' (p. 67)? My opinion is that Keynes is here more traditional than $\mathrm{MH}$ in the sense that he does not make the same distinction between market and forward prices. In addition, he clearly assumes that firms' expectations may be unfulfilled (not at the aggregate level but at the disaggregated one): 'when one is dealing with aggregates, aggregate effective demand at time $A$ has no corresponding aggregate income at time $B$. All one can compare is the expected and actual income resulting to an entrepreneur from a particular decision' (Keynes, 1973, p. 180). Also, 'I now feel that if I were writing the book again I should begin by setting forth my theory on the assumption that short-period expectations were always fulfilled; and then have a subsequent chapter showing what difference it makes when short-period expectations are disappointed' (Keynes, 1973, p. 181).

\section{The Aggregate Supply Function}

My own interpretation is that $Z$ is built as an aggregate function from the entrepreneurs' point of view: assuming $m$ firms, $Z$ is the sum of the $m$ individual supply functions provided that, according to Keynes's adhesion to the first classical postulate, the profit maximisation condition is fulfilled (i.e. marginal cost equal price). Consequently, labour $(N)$ influences $Z$ through its impact on marginal cost as well as on production. $Z$ does not include given prices but a condition on prices: in order to hire $N$, price may equal $w / Q^{\prime}(N)$.

JH's analysis is broadly the same as mine, for instance when he explains that 'unit supply price will grow with employment under conditions of decreasing marginal returns to labour' (p. 730).

For his part, $\mathrm{MH}$ does not make explicit $Z$ specification and properties. It may be read as an aggregate function from the entrepreneurs' point of view in appendix A (eq. A2a, p. 73), but the composition of the "forward offer prices" vector $\left(\mathbf{p}^{\mathbf{s}}\right)$ raises questions: does it include 
functions (as in $\mathrm{JH}$ and $\mathrm{OA}$ specifications where the supply price depends on $N$ ) or rather scalars? In the second case, there should be a problem because profit maximising firms have no degree of freedom to choose $\mathbf{n}$, and $Z(N)$ reduces to one point.

The third appendix does not give any answer, even if $\mathbf{p}^{\mathbf{s}}$ depends on $Y$ (eq. C4, p. 78), because $\mathrm{MH}$ focuses here on market prices for goods which have been already produced, then $N$ is not at stake.

To sum up, I regret that $\mathrm{MH}$ did not clarify $Z$ construction, especially because he puts the emphasis on producers' behaviour in his article.

\section{What do entrepreneurs expect when taking their hiring decisions? The issue about one or two functions on the demand side}

This question has its importance in connection with Keynes's definition of $D$ as 'the proceeds which entrepreneurs expect to receive from the employment of $N$ men' (GT, p. 25). According to the conventional approach, expectations are about consumption $\left(D_{1}\right)$ and investment $\left(D_{2}\right)$. On the contrary, my article (among others) rests on the idea that a distinction between aggregate demand and global expenditures is necessary, just because it is not possible to specify $D=f(N)=D_{1}+D_{2}$ as an aggregate function from the entrepreneurs' point of view.

Indeed, the only way to specify $D_{1}+D_{2}$ as an aggregate function is to aggregate households' consumption behaviour on the one hand, and firms' investment behaviour on the other hand (or households' behaviour if they hold capital goods). For an entrepreneur who is taking his hiring decision, $D_{1}+D_{2}$ may have at best an existence at the global level, for the economy as a whole, before to have some reality at the disaggregated level. Adopting such approach means however that one assumes omniscient entrepreneurs who compute the global expenditure first, and then deduce the share of this global expenditure they carry out. I think it does not match Keynes's entrepreneur picture.

On the contrary, according to the second strand of interpretation, entrepreneurs should not be omniscient. The individual firm's demand function results from an entrepreneur wondering how many workers to hire for a given or expected price, say $p^{\prime}$. For $p$ ', each entrepreneur can compute his receipts depending on how many workers are hired ${ }^{2}$. The aggregation of these individual functions results in $D$ which fits very well with $D$ definition, just as GT's following paragraph ('Now if for a given value of $N . .$. ', GT, p. 25) fits well with firms comparing their proceeds with a maximisation profit condition in order to determine $N$. Several comments must be done here.

a. Let me first underline that the comparison between $Z$ and this definition of $D$ results in the volume of employment at the aggregate as well as at the disaggregate level (because each entrepreneur can build his own $Z$ and $D$ curves $^{3}$ ). At the opposite, a comparison between $Z$ and $D_{1}+D_{2}$ results in employment at the aggregate but not at the disaggregate level. On this subject, the former approach is better for articulating firms' decisions and macroeconomic outcomes.

b. As Section I of Chapter 3 focuses on firms' employment behaviour, and also because Keynes clearly defines $D$ from the entrepreneurs' point of view, I still think that the former

\footnotetext{
${ }^{2}$ Let us recall that a firm can produce and sell any quantity of goods at the market price in a competitive economy.

${ }^{3}$ See OA, pp. 8-9.
} 
approach is more relevant than the second, provided that prices expectations relates to goods which have different delivery dates. In the other case, it would mean that Keynes refers to a hidden function. This is not my interpretation. Indeed, let us recall that Keynes does not mention consumption or investment in Section I of Chapter 3. To my knowledge, he never relates entrepreneurs' expectations to consumption and investment expenditures. Besides, entrepreneur's decision rests on his realised and expected sale-proceeds (GT, p. 51). Or, when changes were unforeseen, the entrepreneur takes price or stock variations into account (GT, p. 123). To sum up, entrepreneurs' decision rest on their own business.

c. It seems to me that $\mathrm{MH}$ takes the same way: 'production and employment decisions are reserved to entrepreneurs, by definition, based on their price expectations' (p. 56). And further: 'each day firms must decide, in a short-period equilibrium process that Keynes calls 'the principle of effective demand', how much employment to offer today based on their expectations of the market prices they will receive for the heterogeneous finished output that will emerge at the end of the various production periods' (p. 60). Employment does not depend on entrepreneurs' expectations about propensity to consume or investment. On the contrary, changes in consumption or investment entail changes in market and forward prices, and then changes in entrepreneurs' behaviour. To sum up, what $\mathrm{MH}$ calls the aggregate demand function (i.e. $D_{1}+D_{2}$ ) does not refer to 'the proceeds which entrepreneurs expect to receive from the employment of $N$ men'. On the contrary, it seems that MH makes an implicit use of 'my' specification of $D$.

d. I again ask MH how he defines $\mathbf{p}^{\mathbf{s}}$. In the event of a scalars vector, I wonder if MH did not merge $Z$ and 'my' specification of $D$ in the same function: $\mathbf{p}^{\mathbf{s}}$ being given, firms choose $\mathbf{n}$ in order to maximise their profit and $Z(N)$ reduces to a point which is the effective demand.

e. For his part, JH seems to share my interpretation when he writes, without any mention to the propensity to consume, that 'if an entrepreneur takes the demand price as exogenously given, total expected sales proceeds will be a linear function of the quantity produced, and hence a concave function of the level of employment if decreasing returns to labour are assumed. Aggregation of the individual entrepreneur's expected demand curves leads to an aggregate demand curve $(D)$...' . But, the continuing citation is really puzzling as he asserts that ' $[D]$ is concave as long as the marginal propensity to consume is smaller than one' (p. 733). From my point of view, JH makes confusion between the two distinct functions because the propensity to consume has nothing to do here. Moreover, one can wonder why he questions the concavity of $D$ while he gives a clear explanation two lines above. In some sense, in is interpretation, the $D$ function is over determined.

Then, JH omits to mention that Casorosa's critics do not concern some inconsistency in the construction of $D$, but the conventional interpretations which view 'the expected demand function as the entrepreneurs' expectation of the expenditure function' (Casarosa, 1981, p. 192). On the contrary, Casarosa pleads on an accurate distinction between the two functions, as I do in my article.

\section{The closure of the system, temporary equilibriums and convergence}

Assuming that individual firms do not directly expect $D_{1}+D_{2}$ raises an important interrogation about the closure of the system: it should be proved that these firms adjust their production in order to respond to exogenous changes in consumption or investment. My 
feeling is that Keynes did not give a formal proof but was sure that firms respond properly ${ }^{4}$. It was the main goal of my article to make explicit such formal proof while Keynes just gives some indications in Chapters 5 and 10 (Section IV).

MH presentation about overlapping production period shows the complexity of the issue: 'aggregate effective demand and income are not commensurable because they do not have the same dimensions in time' (p. 62). This probably explains why Chapter 3 does not include any consideration about system closure or balance accounting.

I admit confusion in my article because I wrongly assumed that each production period lasts only one day. But, because GT is a general theory, it has to correctly work under this simplifying assumption as well as in a more complex framework. My analysis should then not be considerate as wrong, just as incomplete.

As a result, the temporary equilibrium analysis in my article (macroeconomic changes induce today prices or stocks adjustments which affect tomorrow firms' behaviour) remains relevant. The analysis is also consistent with several quotations from GT. For instance, in the case of unforeseen expansion in the capital goods industries, 'the efforts of those newly employed in [these] industries to consume a proportion of their increased incomes will raise the prices of consumption-goods until a temporary equilibrium between demand and supply has been brought about partly by the high prices causing a postponement of consumption, partly by a redistribution of income in favour of the saving classes as an effect of the increased profits resulting from the higher prices, and partly by the higher prices causing a depletion of stocks' (GT, p. 123-124).

This approach seems also consistent with MH's analysis of the multiplier: 'the multiplier is a market period (ex post) relationship between the realised values of consumption and investment output, which may well influence the state of expectation, but is not directly itself a causal element of the principle of effective demand' (p. 70).

In short, I think that, in the 'theoretical world', an unforeseen change in investment results in the following outcomes.

a. The principle of effective demand holds provided that employment is determined by today entrepreneurs' expectations.

b. As change in investment is unforeseen, it results in market adjustments on prices and/or stock of inventories (temporary equilibrium).

c. Entrepreneurs take these market adjustments into account when formulating their expectations tomorrow morning, hence the convergence toward an equilibrium where expectations are fulfilled ${ }^{5}$.

It seems to me that $\mathrm{JH}$ agrees with this interpretation, for instance as he writes that: 'the quantity reactions do not take place within the production period but - if at all - in the transition from one period to the next' (p. 736). On the contrary, MH's approach diverges at least in two ways.

- MH restricts the principle of effective demand to the first item (a), while I include (maybe wrongly) the three items.

\footnotetext{
${ }^{4}$ Someone told me that Joan Robinson said she had to be compared to a horse (laboriously digging her furrow) while Keynes was a tiger (brilliant but not really interested in details). If someone knows the reference, I would be happy to have it.

${ }^{5}$ Things are of course more complex in the 'real world' where entrepreneurs have to take into account many parameters and changes at the same time.
} 
- According to $\mathrm{MH}$, the causation runs from, say, yesterday evening results to today expectations. Then, these expectations will be fulfilled today evening because production is undertaken forward orders. To my standpoint, today expectations may be unfulfilled this evening because production is not undertaken forward orders.

Eventually, I would like to ask MH if he thinks that, in GT (if not in the only Chapter 3), there is a theoretical step by step adjustment of the type I described above. Moreover, I think his distinction between employers and dealers allows him to drop artificially the adjustment problem out of the story.

\section{The specification of the consumption function and the two demand functions once again}

Considerations about temporary equilibriums lead to questions about the consumption function specification. Indeed, $N$ being given, the value of firms' receipts $(R)$ may change because of market prices adjustment. For convenience, let us assume that the whole receipts are distributed to households (through wages and profits) and that consumption behaviour only rests on a given marginal propensity to consume $(c)$. Under these assumptions, the value of consumption expenditures $\left(D_{1}\right)$ depends on the price level as well as on employment:

$$
D_{1}=c \cdot R=c \cdot p \cdot Q(N)
$$

In other words, for any given $N$, an increase of the current market price entails a rise of $R$ and then of $D_{1}$, although consumption remains unchanged in real terms. Many important implications should be underlined.

a. Households are indifferent to the price level when they take their consumption decision. They just take the market price as given, without any effect on their real consumption. This outcome echoes the interpretation of many Keynesians who claim that prices are set (or proposed) by entrepreneurs. It reinforces also my own interpretation about the $D$ function. Accordingly, I think that $\mathrm{JH}$ and $\mathrm{MH}$ are wrong when they put a demand price in their demand function ( $\mathbf{p}^{\mathbf{d}}$ in MH's model, p. 73).

b. More precisely, one can still think that prices are set on the market. But, at the macroeconomic level, buyers' price is not independent from sellers' price. Everything happens as if sellers propose their own price. If it is too low, the closure of the system entails an excess demand (which may be solved by an increase of the price or by a drawing from the stocks of goods $)^{6}$.

c. As a crucial result, $D_{1}$ (in nominal terms) does not exist before a price has been proposed to households. Then the function $\left(D_{1}+D_{2}\right)$ cannot be drawn on the N/Z diagram. Consequently, there is no possibility for a unique intersection point between $\left(D_{1}+D_{2}\right)$ and $Z$. Effective demand cannot be defined in the way which has been taken by $\mathrm{JH}$ and $\mathrm{MH}$ among many others.

The main critic I address to $\mathrm{MH}$ and $\mathrm{JH}$ articles may be that they do not take this closure difficulty into account. How do they specify the demand price $\mathbf{p}^{\mathbf{d}}$ ? Do they think that $D_{1}$ can be defined independently of $Z$, and how?

\footnotetext{
${ }^{6}$ At the microeconomic level, the rules remain those of handbooks: the income and general level of price being given, relative prices determine the composition of the basket of consumption goods, and changes in relative prices entail substitutions between goods.
} 
d. One can eventually argue Keynes specifies $D_{1}$ as a function of $N$ rather than $R$, that is $D_{1}=$ $\chi(N)$. Does it mean that Keynes made a mistake? I do not think so. My interpretation is that the two first sections of Chapter 3 have different goals

- In Section I, Keynes focuses on firms' production behaviour. He attempts to prove that his theory will not depart from competitiveness and profit maximisation hypotheses even if its analysis refers to the whole economy. In other words, he explains the mechanisms at stake in the first classical postulate.

- In Section II, he summarises the macroeconomic theory which will essentially be developed in Books III and IV.

Indeed, Keynes gives the impression that issues about competitiveness and profit maximisation are definitely solved at the end of Section I. That allows him to adopt another point of view in Section II which begins as follow: 'A brief summary of the theory of employment to be worked out in the course of the following chapters...' (GT, p. 27). Above all, that allows him to put $p$ ' (resulting from Section I) in the consumption function which therefore only depends on employment level: $D_{1}=c \cdot p^{\prime} \cdot Q(N)=\chi(N)$.

\section{Conclusion}

My actual state of mind may be summarized in the next points.

a. I am still convinced that GT faces a closure difficulty between the macroeconomic outcomes and the microeconomic behaviour of firms. In short, individual firms' behaviour could not directly depend on consumption and investment expenditures because they do not have any reality at first at their level, hence the necessity to make a distinction between the global expenditure and the aggregate demand functions.

b. Did Keynes have the same concern? Nobody knows. But two points must be underlined in the event of a negative answer:

- A function such as $D=D_{1}+D_{2}$ cannot be built as an aggregate from the entrepreneurs' point of view.

- Owing to a problem of price determination, $D_{1}$ cannot be determined independently from $Z$. One can perhaps skip 'my' interpretation of $D$, but only if the link between $D_{1}$ and $Z$ is made explicit.

c. I still think that employment is always at equilibrium, provided that equilibrium refers to the intersection between $Z$ and $D$.

d. However, resulting from a closure necessity, expectations may be unfulfilled (at the end of the day as well as later). The topics of temporary equilibrium and convergence toward fulfilled expectations then remain relevant.

\section{References}

Allain O. (2009) "Effective Demand and Short-term Adjustments in the General Theory", Review of Political Economy, 21(1), pp. 1-22.

Casarosa, C. (1981) The microfoundations of Keynes's aggregate supply and expected demand analysis, Economic Journal, 91, pp. 188-194. 
Hartwig J. (2007) "Keynes vs. the Post Keynesians on the Principle of Effective Demand", The European Journal of the History of Economic Thought, 14(4), pp. 725-39.

Hayes M. (2007) “The Point of Effective Demand”, Review of Political Economy, 19(1), pp. 55-80.

Keynes, J. M. (1936) The General Theory of Employment, Interest and Money (London: Macmillan).

Keynes, J.M. (1973) The Collected Writings of John Maynard Keynes, Vol.14 (London: Macmillan). 